Spanish Philosophy in Times of Crisis.

"Orteguian" Lessons for Today

\title{
La filosofía española en tiempos de crisis. Lecciones "orteguianas" para la actualidad
}

Manuel Artime Omil

\author{
UNED Pontevedra \\ martime1@hotmail.com
}

DOI: http://dx.doi.org/10.15366/bp2018.18.013

Bajo Palabra. II Época. No18. Pgs: 273-290

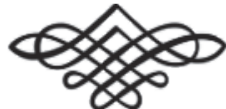


Recibido: 09/05/2018

Aprobado: 29/07/2018

\section{Resumen}

La filosofía española ha respondido a la crisis con una movilización institucional y una reivindicación de su valor social. No obstante, el papel que la sociedad asigna a la filosofía ha experimentado importantes cambios entre nosotros y sigue siendo motivo de controversia hoy. Ortega nos ofrece un modelo de filosofía para (y en) tiempos de crisis que quizá tenga valor para nuestro debate actual.

Palabras clave: filosofia española, sociología filosófica, herencia "orteguiana", ontología del presente, genealogía cultural.

\section{Abstract}

Spanish philosophy has responded to the crisis with an institutional mobilization and a vindication of its social value. Nevertheless, the role that society assigns to philosophy has undergone important changes in our recent past, and continues to be controversial today. Ortega y Gasset offers us a philosophy model for (and in) times of crisis, which may have value for our current debate.

Keywords: Spanish philosophy, philosophical sociology, the inheritance of Ortega and Gasset, ontology of the present, cultural genealogy. 
"Es interesante asistir históricamente a este proceso y ver cómo lo que luego va a ser un principio puro empieza por ser un uso mágico, un apetito particular... Habria que hacer una genealogía de la cultura"

\section{Introducción}

LA SOCIEDAD ESPAÑOLA ESTÁ INMERSA en un proceso de transformación profunda en los últimos años. Nuestros órganos institucionales y culturales atraviesan un periodo de inestabilidad y cuestionamiento, al que no es ajeno ningún ámbito del saber, o al menos, ninguna ciencia social puede darse por desentendida. La filosofía espańola participa de este proceso de reflexión, no sólo respecto a los cambios que acontecen a su alrededor, sino respecto a sí misma y el papel que ha de jugar en nuestra sociedad. Es en este contexto donde hay que entender la creación y creciente protagonismo de la Red Española de Filosofía. La comunidad filosófica española ha encontrado en este órgano vertebrador la plataforma para trasladar su voz a la esfera pública y denunciar la marginación filosófica en el ámbito educativo. Pero además — y este es el hilo en que se inserta este artículo— se ha conseguido suscitar un debate, tanto de difusión académica como mediática, sobre cuál es el lugar que corresponde a la filosofía, cuál es su relación con otros saberes y qué puede esperar de ella la sociedad ${ }^{2}$.

En la primera parte del texto tomaremos como referencia dos estudios sobre historia filosófica española, Herederos y pretendientes y La norma de la filosofía ${ }^{3}$, en los que se aborda expresamente este aspecto de cómo se ha ido transformando el

\footnotetext{
Estudio realizado en el seno del proyecto de investigación: 'El legado filosófico del exilio espańol de 1939: razón crítica, identidad y memoria’. EXFILO. (2016FFI-77009-R). Investigador principal: Antolín Sánchez Cuervo (CSIC. Instituto de Filosofía). Convocatoria: 2016 Proyectos de EXCELENCIA y Proyectos RETOS (Plan Nacional I+D financiado por el Ministerio de Economía, Industria y Competitividad).

1 Ortega y Gasset, J.: El tema de nuestro tiempo, Alianza, Madrid, 1981, p. 111.

2 Un testimonio del debate académico puede encontrase en Campillo, A. y Manzanero, D. (coordinación general) 'Actas del I Congreso internacional de la Red española de Filosofía', http://redfilosofia.es/congreso/actas/ El debate de prensa está siendo referenciado por la propia REF en su sección de artículos http://redfilosofia.es/ archivoldocumentos/articulos/

${ }^{3}$ Moreno Pestaña, J. L.: La norma de la filosofía. La configuración del patrón filosófico español tras la Guerra Civil, Biblioteca Nueva, Madrid, 2013. Vázquez, F. La filosofía espańola: herederos y pretendientes. Una lectura sociológica (1963-1990), Abada, Madrid, 2009.
} 
papel de la filosofía entre nosotros. El método de Sociología Filosófica que siguen sus autores, Francisco Vázquez y J.L. Moreno Pestaña, invita a considerar el trabajo de los filósofos junto a las expectativas que la comunidad académica deposita sobre ellos. Se asume que el reconocimiento adquirido por un trabajo científico vendrá condicionado por factores de carácter social o gremial, que pueden ser identificados en forma de "patrones" o "normas" estipuladas por dicha comunidad epistémica. Así, la comunidad filosófica española habría ido estipulando en cada momento histórico unas determinadas "reglas del club", que dictaminan cuál es el papel que ha de jugar el filósofo o cuáles los requisitos que determinan su aceptación como tal.

Una de las conclusiones a la que llegan estos dos libros — concebidos bajo un proyecto común ${ }^{4}$ y que pueden leerse con continuidad histórica- es que el patrón filosófico que predominaba en Espańa en el primer tercio de siglo, experimentará una quiebra con la llegada de la dictadura, sin que se haya podido recuperar después de ésta. El franquismo supondría el abandono del "patrón orteguiano", caracterizado por su vocación de intervenir sobre la realidad histórica concreta y por el diálogo con otros saberes sociales. El patrón posterior, franquista, rompería con este dictatum de intervención concreta, reservando para la filosofía un papel más especulativo, modelo que se habría venido arrastrando hasta hoy. Uno de los objetivos de este artículo - escrito desde la admiración y el afecto a los autores referenciados- es conjeturar la recuperación actual, como ha sucedido puntualmente en otros momentos, de un modelo de filosofía consagrada a reflexionar sobre nuestro tiempo y sobre el papel que ella misma viene jugando en éste; o dicho de otro modo, conjeturar el retorno actual a una filosofía "orteguiana" (quizá) sin Ortega. Para seguir esta pista — defendemos— será preciso ampliar los límites del enfoque sociológico científico y atender a las demandas culturales o de contexto, que empujan a la filosofía a actuar como un pensamiento de (y en) crisis.

En este sentido, la genealogía cultural del "patrón orteguiano" nos ofrece un interesante espejo en el que mirarnos; siempre y cuando ese reflejo no impida ver las distancias entre ambos contextos, entre la crisis de principios del XX y la de hoy. Serían razones de índole histórico-cultural, razones políticas en último término sostendremos-, las que inciden sobre la comunidad de filósofos, y por ende, sobre el tipo de respuestas que de éstos se demanda, particularmente en momentos de crisis. Si la filosofía orteguiana es un pensamiento volcado sobre la temporalidad, la circunstancia, es básicamente por la conciencia de declinar epocal que se vive en

\footnotetext{
${ }^{4}$ Estudios insertados en el proyecto de investigación con título 'Intelectuales y calidad democrática en la España contemporánea', que tendría por objeto de entender de manera conjunta las transformaciones del ámbito filosófico y las tomas de posición política por parte de los filósofos españoles.
} 
dicho momento. La filosofía estaría concernida por la crisis; lo cual quiere decir no sólo que deba prestarle atención desde fuera sino examinar críticamente cuál ha sido su papel en ella, en qué ha contribuido al agotamiento de la época, por qué se ha ido apagando su luz sobre la realidad.

El rejuvenecimiento de la filosofía, para Ortega, pasa precisamente por recuperar su sentido histórico, el pulso de la vida, que es lo que había perdido la cultura dominante de finales del XIX. Hoy estaríamos asistiendo, mutatis mutandis, a un proceso similar, al declinar de otra (tardo) modernidad, donde se pone en entredicho lo que parecía firme y que empuja a la autocrítica a los diferentes saberes. No es la primera vez que esto sucede, hemos asistido a otras impugnaciones de lo heredado y otros procesos de autocrítica en nuestro pasado reciente. $Y$ otras veces hemos tenido también el impulso de pensar que lo moderno nacería definitivamente con nosotros. Hemos de confiar — con Ortega — que la historia nos ayude a ir aplacando estas tentaciones adanistas.

\section{La mirada sociológica sobre la filosofía española del siglo pasado}

Los trabajos de Francisco Vázquez y J.L. Moreno Pestaña comparten un enfoque metodológico, que toman de la sociología de la ciencia y que aquí trasladan a la filosofía española ${ }^{5}$. La idea es que la historia del pensamiento no es sólo la historia de unos saberes sino de una comunidad humana, con sus normas, subgrupos, estructuras institucionales, patrones de conducta, medidas de inclusión y exclusión ${ }^{6}$. En la tarea del historiador del pensamiento deberíamos incluir por tanto la de reconstrucción de ese universo humano donde encuentran acogida las ideas. Se trata —en terminología sociológica extraída de Bourdieu — de identificar los habitus intelectuales y de acción establecidos dentro de esa comunidad ${ }^{7}$.

\footnotetext{
${ }^{5}$ Ambos autores toman como referencia directa los trabajos de Bourdieu, Randall Collins y Martin Kusch, pero remontan este tipo de enfoque al Tratado teológico-político de Spinoza y su intención de elaborar una historia inmanente y materialista de la filosofía. "[En el discurso] se superponen diferentes juegos del lenguaje: lenguajes teóricos, políticos, estéticos, vitales,...: el trabajo sociológico es una de las maneras de desenredarlos analíticamente", Moreno Pestańa, J.L.: La norma de la filosofía..., op.cit., p. 23. "Una dimensión importante en la vida intelectual propia de los campos filosóficos es el trabajo continuo para instituir o desestabilizar las fronteras establecidas, de modo que la estructura jerarquizada de los bienes que circulan en el campo dista de ser rígida [...] Se propone un análisis de la estructura interna del campo filosófico y de su evolución", Vázquez, F.: La filosofía española..., op. cit., p. 31.

6 “Toda normalización se asienta en una escisión entre valores pretendidos y valores rechazados”, Vázquez, F.: 'Javier Muguerza y la normalización de la filosofía espańola' en Rodríguez Aramayo, R. y otros (ed.): Diálogos con Javier Muguerza, CSIC, Madrid, 2016, p. 153.

7 "El habitus es una matriz de disposiciones que actúan como esquemas de acción y del pensamiento en los agentes sociales considerados”. Vázquez, F.: La filosofía espańola..., op. cit., p. 27.
} 
El subtítulo de la obra de Moreno Pestaña, "la configuración del patrón filosófico tras la Guerra Civil", nos anticipa el periodo que se somete a análisis sociológico. Según este enfoque, la dictadura deja su sello también en la filosofía, sustituyendo un patrón de conducta "orteguiano" por otro de inspiración "neotomista". Lo que nos permite hablar de cambio de "patrón filosófico" es que cambian no sólo los contenidos sino la tarea misma del filósofo. Su cometido deja de ser, como se había inculcado bajo el magisterio de Ortega, hacerse cargo de la realidad en curso, reflexionar sobre el sentido de nuestro tiempo. El objeto de la filosofía es otro, de acuerdo a los dictados del "neotomismo", es ocuparse de lo intemporal, lo trascendente, lo eterno. Para disgusto de Ortega este nuevo patrón será asumido por buena parte de su discipulado, principalmente aglutinado en torno a Zubiri, como Laín, Arboleya, Conde,..., mientras los que no se atienen al modelo verán sacrificada su carrera académica, como es el caso paradigmático de Julián Marías. Ortega identifica en este nuevo modelo de filosofía un giro reaccionario, y no sólo por la implantación de la doctrina teológica por parte de los "neotomistas", sino por cuanto supone situar la mirada más allá de lo temporal, de toda consideración histórica, como aboga la vía metafísica abierta por Zubiri. El "escolasticismo", en su versión teológica u ontológica, consistirá en hacer de la filosofía una ciencia de conceptos eternizados, sin considerar el contexto en que se gestan las ideas, ni en el que son recibidas ${ }^{8}$.

Como resultado de la guerra se produce por tanto una quiebra en la filosofía española y en el rol social asignado al filósofo. De acuerdo al nuevo patrón disciplinario, impulsado por el escolasticismo, la filosofía consiste estrictamente en el comentario de un canon de autores o temas de referencia. Luego, el pensamiento orteguiano debe ser rechazado no sólo por representar una tradición liberal y secularizante, sino también por criterios disciplinarios, por no satisfacer requisitos metodológicos ${ }^{9}$. El Padre Ramírez, nuevo hegemon de la filosofía española, se ocupará de la desvalorización del pensamiento "orteguiano" por asistemático, carente de fundamento, "ontofóbico". El buen filósofo es el que contribuye a sustentar las bases, ya sean epistemológicas u ontológicas, del gran edificio del saber. Los ensayos "orteguianos", trufados de reflexiones históricas y una retórica literaria, no alcanzan la categoría de filosofía, son tan sólo una sucesión de "metáforas" sin valor

\footnotetext{
${ }^{8}$ El rechazo de Ortega hacia la Iglesia tendría que ver con el modelo de pensamiento que promulga, pero que no se agota en ella, un escolasticismo que "no ayuda a pensar, sino a producir términos que permitan gobernar y prefiere los administradores que los genios”, Moreno Pestaña, J.L.: La norma de la filosofía..., op. cit., p. 156.

9 "Los críticos de Ortega se consideraban intelectuales solventes, capaces de responder a los desafíos filosóficos del momento con mayor altura que Ortega. Representan así una vía hacia la actualidad filosófica para la que el modelo orteguiano resulta insatisfactorio; fundamentalmente, por carencias formales y teóricas: por ser poco sistemático y excesivamente historicista”, Moreno Pestańa, J.L.: La norma de la filosofía..., op. cit., p. 131.
} 
epistémico — sentencia García Escudero ${ }^{10}$ —. Aunque Ortega acabe por volver a la España de Franco, el "orteguismo" permanecerá desterrado de la academia filosófica franquista.

La otra obra aquí referenciada, la de Francisco Vázquez, si bien publicada con anterioridad, aborda el periodo posterior al que acabamos de ver, 'La filosofía espańola... (1963-90)'. Esta etapa vendría marcada por la pugna de dos grupos, los "herederos y pretendientes" ${ }^{11}$, en liza por la hegemonía del campo filosófico español. "Herederos" - llama Vázquez- al grupo conformado por los discípulos directos de la corriente escolástica, donde se va a producir una paulatina sustitución de materiales (autores de la metafísica contemporánea en lugar de la tomista) pero no de modelo: filosofía como saber puramente especulativo y filósofos como comentaristas de un canon.

Frente a estos, se irá forjando una red filosófica alternativa, los "pretendientes", que aspiran a devolver la filosofía española a la tradición ilustrada y liberal, a sacarla de su aislamiento respecto a la filosofía europea del momento. Aranguren es la figura impulsora de este nuevo grupo, que habrá de dar los primeros pasos desde la periferia académica (Centro Estudios Políticos, Instituto Humanidades, Cuadernos Diálogo, Revista Occidente,...), pero que termina por sustituir a la red oficial con la consecución de la democracia ${ }^{12}$.

La interesante conclusión — para el tema que aquí se discute- que se desliza de la lectura de estos dos libros, es que la emergencia de este nuevo grupo va a suponer un desplazamiento en los fundamentos filosóficos, hacia contenidos seculares y humanistas, más compatibles con los tiempos democráticos, pero no supondrá demasiado cambio en el patrón metodológico respecto al pasado inmediato, ni la recuperación del rol social del filósofo previo a la dictadura. En esta

\footnotetext{
${ }^{10}$ La expresión habrá de ser replicada por el propio Ortega en un texto de 1947, no publicado en vida: "Pensar que durante más de treinta años he tenido que soportar en silencio, nunca interrumpido, que muchos pseudointelectuales de mi país descalificaran mi pensamiento, porque 'no escribía más que metáforas' -decían ellos. Esto les hacía triunfalmente proclamar que mis escritos no era filosofía. Parece mentira que ante mis escritos nadie haya hecho la generosa observación que es de que en ellos no se trata de algo que se da como filosofía y resulta ser literatura, sino por el contrario, de algo que se da como literatura y resulta que es filosofía", Morán, G.: El maestro en el erial. Ortega y Gasset y la cultura del franquismo, Tusquets, Barcelona, 1998, p. 373.

${ }^{11}$ El grupo de los 'herederos' estaría conformado por la red oficial: Milán-Puelles (fenomenología), Rábade (Heidegger),... Mientras que los 'pretendientes' formarían una red alternativa, en torno al discipulado de Aranguren: Muguerza (ética), Garrido y Deaño (fa analítica), Elías Díaz (fa jurídica), Cerezo (fa moderna), R. Ventós (estética), Sotelo (fa política),...

12 El profesor Santesmases matiza a este respecto, que el discipulado oficial mantendrá durante el periodo democrático todavía: "una presencia relevante en el ámbito de la filosofía política (Alejandro Llano), la filosofía del derecho (Andrés Ollero) y la filosofía de la educación (José Antonio Ibánez Martín) y también en la interpretación de la historia de España. [...] sería un error pensar que esa posición desapareció en el proceso de transición a la democracia”, García-Santesmases, A.: 'La transición filosófica. Reflexiones político-intelectuales', Circunstancia, 30, 2013.
} 
nueva etapa la filosofía ha dejado de concebirse como base de todos los demás saberes, el tronco del árbol de la ciencia, para pasar a ser una rama paralela, un saber específico (con subdivisiones), que dará lugar a sus propios expertos ${ }^{13}$. Esta "nueva" concepción de la filosofía como saber erudito reserva al filósofo un dominio de conocimiento acotado, propio (relativo a fundamentos antropológicos u ontológicos) y lo mantiene alejado de la interlocución con lo temporal, lo histórico, y del presente. Al igual que sucede con tantos otros ámbitos de la cultura ${ }^{14}$, el retorno de la democracia no supone recuperar el modelo epistémico que precedió a la dictadura. La vieja vocación orteguiana por problematizar el tiempo en que estamos inmersos, permanecerá irrecuperable. Es en este sentido que Jesús Díaz habla de una "segunda muerte de Ortega" ${ }^{15}$, para describir un proceso de renovación filosófica que significa dejar atrás el impulso más renovador y original que ha conocido la filosofía española.

\section{Genealogía cultural orteguiana}

El anÁlisis del PROFesor VÁzQuez se detiene en los años 90, pero siguiendo el espíritu de aquel proyecto ('Los intelectuales y la calidad democrática en el España contemporánea') cabría hacerlo extensivo hasta nuestros días y preguntarse en qué medida somos hoy deudores de aquel patrón filosófico. Han transcurrido ya treinta años desde entonces, casi dos generaciones, si tomamos la medida orteguiana. Parece tiempo suficiente para que se hayan dado cambios, pero quizá no disponemos aún de la perspectiva para valorarlos. No podremos prolongar el análisis sociológico al presente, hasta que se haya consumado el relevo generacional en las cátedras. Esto nos sirve aquí de excusa para proponer un cambio de enfoque; y es que la Sociología Filosófica ha proporcionado resultados reveladores y estimulantes, pero presenta algunas limitaciones respecto al propósito que se plantea: reflexionar sobre las claves de nuestra cultura democrática. Este texto quiere ser una invitación a ampliar el foco de análisis, más allá de los muros de las facultades. La reconstrucción de las redes filosóficas y los hábitos epistémicos a los que éstas han dado lugar, puede proporcionar una imagen un tanto enclaustrada o academicista de la comunidad

\footnotetext{
13 "Lo que prima en los últimos años es una tendencia a la fragmentación en subcampos cada vez más específicos y pretendidamente desideologizados: investigaciones sobre Ciencia, Tecnología y Sociedad, sobre Teoría de la Democracia, sobre Bioética, sobre Estética y Nuevas Tecnologías, sobre Ética y Ciudadanía, etc.”, Vázquez, F.: La filosofía espańola..., op. cit., p. 400.

${ }_{14}$ Artime, M.: Espańa. En busca de un relato, Dykinson, Madrid, 2016, (Introducción).

15 Díaz Áltvarez, J.: ‘Las dos muertes de Ortega, a propósito de la norma de la filosofía', Revista de Estudios Orteguianos, 28, 2014.
} 
filosófica. O dicho de otra forma; existen factores de origen extra-académico que influyen decisivamente en el trabajo del filósofo, y que sobre todo — sostendremos aquí- se hacen notar en determinados momentos históricos. El enfoque sociológico nos proporciona una valiosa explicación de cómo ha cambiado el patrón filosófico, pero quizá no tanto de por qué lo hace. Resulta escaso respecto a las razones históricas, culturales o políticas, que empujan nuestro trabajo, pues no sólo son las profesionales o específicas. Para hacerse cargo de los cambios que pudieran estar acaeciendo en el patrón y en los roles de la filosofía española hoy, es preciso tomar en consideración las demandas que le llegan al filósofo de una sociedad en crisis. Si bien las crisis sociales no tienen por qué coincidir con las epistémicas, la filosofía tampoco es sorda a la responsabilidad epocal. Para ilustrar esto encontramos un buen ejemplo en el propio Ortega, cuyo proyecto filosófico se encarna en un contexto de crisis; y tomará como la más urgente de sus obligaciones, el hacerse cargo de esta circunstancia — primero española, luego europea-.

"Creo muy seriamente que uno de los cambios más hondos del siglo actual con respecto al XIX va a consistir en la mutación de nuestra sensibilidad para las circunstancias", advertía Ortega en Meditaciones del Quijote (1914) ${ }^{16}$. Si hay un elemento transversal al pensamiento espańol del momento es la conciencia de crisis, la evidencia de un agotamiento epocal que necesita ser pensado; y es ahí donde el joven Ortega va a erigirse en verdadero protagonista. Esta conciencia de crisis le lleva a romper con la Restauración y con su propia familia; es decir, con aquella tradición liberal que está de tal modo integrada en el régimen que ha perdido el pulso de la historia, la capacidad para renovarlo. Concebido desde la derrota en la última revolución, el liberalismo posibilista se aviene al pacto restaurador como solución de orden. Pero el avance del nuevo siglo — como advierte Ortega - pone en evidencia su incapacidad para adaptarse a las transformaciones sociales, hasta devenir en un repliegue autoritario.

Esta crisis social e histórica se va a manifestar también en la filosofía; y por extensión — afirma Ortega — en todos aquellos saberes que quieran evitar verse arrastrados por la decadencia del orden histórico que habitan. Desde el punto de vista filosófico, la Restauración significó la implantación y arraigo del positivismo, que ha de entenderse - propuso Abellán - como la ideología de la clase dominante ${ }^{17}$. Según este patrón, la filosofía habría de estar supeditada a la ciencia. "La filosofía debe ir recogiendo y examinando los resultados de la ciencia y desarrollando el método científico y sus principios, que a su vez, pueden influir de nuevo en las

\footnotetext{
16 Ortega y Gasset, J.: Obras completas. Tomo 1, Revista de Occidente, Madrid, 1966, p. 319.

17 Abellán, J.L.: Historia crítica del pensamiento español. Vol. V. (tomo 1), Espasa, Madrid, 1989. pp. 74 y ss.
} 
ciencias después de haber sido fecundados por ellas" — dirá del Perojo— ${ }^{18}$. La labor del filósofo, de acuerdo a la cultura oficial, debe ceñirse a la síntesis y metodología científica. Tras los excesos de la filosofía idealista y revolucionaria, de la metafísica secularizada del XIX, se impone a final del siglo un retorno al kantismo, a la filosofía como analítica del saber positivo y la razón universal que éste trae consigo ${ }^{19}$.

La problematización del positivismo, que se abre con el nuevo siglo, no puede circunscribirse a una empresa académica, sino que es expresión de un movimiento de regeneración o impugnación de la cultura oficial, con un sentido —advierte pronto Ortega ${ }^{20}$ — nítidamente político. El positivismo es algo que permea todos los ámbitos de la existencia, es el modo de vida o "moralidad" — dirá Aranguren ${ }^{21}$ — de la burguesía industrial emergente; asociada a los valores de la competencia, eficiencia, técnica, etc., por contraposición a la vieja burguesía rentista, cuyo declinar encontramos descrito en las novelas de Galdós. El positivismo como cultura oficial tendrá múltiples extensiones; en el ámbito estatal o burocrático (jovellanismo), judicial o legal (Escuela de Estudios Jurídicos), natural o biológico (darwinismo), social o humanista (spencerismo), psicológico (fisiologismo),... La universidad es otro más de los ámbitos que se ven sumergidos en esta ola de los "saberes útiles", y que tiene a la Iglesia como único oponente, obstinada en recuperar un monopolio perdido. La cultura canovista es descrita por Aranguren como un "positivismo conservador", que intenta compaginar esas dos fuerzas sociales, burguesía e Iglesia, propiedad y fe, no siempre en fácil comunión. Pero resulta una cultura cohesionada por su voluntad reactiva hacia otras latencias sociales del momento (regeneracionismo, obrerismo, reformismo democrático,...). La descripción que hace Aranguren de este patrón cultural (y político) positivista, de impronta anglosajona — señala—, va a subrayar sus efectos "desmoralizantes" para la sociedad española de la época; una desmoralización, que tiene su mayor expresión en la esclavitud o mercantilización de personas, pero que se refleja también en la instrumentalización y frustración que el utilitarismo político ("benthamiano") supone para las esperanzas humanas, en la tecnificación social como respuesta del liberalismo de fin de siglo a la tensión generada por las demandas democratizantes ${ }^{22}$.

${ }_{18}$ Cita extraída del artículo de José del Perojo: 'Objeto de la filosofía en nuestros tiempos', Revista Europea, 70, 1875, p. 646. Están también recogidas en Núñez Ruíz, D.: La mentalidad positiva en Espańa: desarrollo y crisis, Tucar, Madrid, 1975.

19 Núñez Ruíz, D.: La mentalidad positiva en España..., op. cit. Villacańas, J.L. (coord.): Kant en España: el neokantismo en el siglo XIX, Verbum, Madrid, 2006.

${ }^{20}$ Ortega y Gasset, J.: 'Vieja y nueva política', Obras completas. Tomo 1, op. cit., pp. 265-299.

${ }^{21}$ López Aranguren, J.L.: Moral y sociedad. La moral española en el siglo XIX, Cuadernos para el diálogo, Madrid, 1966.

22 La crítica de Aranguren a esta cultura positivista o utilitarista del periodo de Restauración enlaza con otras críticas del autor dirigidas a la cultura tecnócrata del momento como Memorias y esperanzas espańolas, Taurus, Madrid, 1969. 


\section{Modernismo orteguiano}

El positivismo ofrecía a la Restauración un programa de "modernización" cultural y política, pero con el cambio de siglo esas ideas se presentan como agotadas, "carbonizadas" - dirá Ortega—, sin respuesta para los cambios sociales en marcha. Cincuenta años atrás, la inteligencia liberal de vanguardia encuentra en los saberes positivos un baluarte en la lucha contra el confesionalismo reaccionario. La filosofía positivista saldrá triunfante de la —llamada - querella de la "Ciencia Española", convertida en cultura oficial. Pero de esa sociedad tecnificada surgirán nuevos desafíos y nuevas demandas, que la mentalidad positiva no está en situación de recibir, incapaz de ver más allá de lo dado.

Es en este sentido que Ortega se declara "nada moderno y muy siglo XX"; lo que se presentaba como "moderno" ha experimentado un envejecimiento acelerado, que Ortega achaca a su presunción de intemporalidad, de verdad eterna y, por tanto, a su renuencia a los cambios. "La cultura pervive mientras recibe constante flujo vital de los sujetos. Cuando se interrumpe, y la cultura se aleja, no tarda en secarse y hieratizarse" 23 . El anquilosamiento de la cultura moderna, su falta de flexibilidad, es consecuencia de esa pretensión de situarse fuera del flujo de vida, fuera de la historia. Como el Barón de Munchausen — dice Ortega refiriéndose a aquel marino de leyenda que se tiraba de su propia coleta para sacarse del agua"el pensador moderno se obliga a sí mismo a salir al absoluto Fuera" ${ }^{24}$. En virtud de esta sublimación, de este situarse fuera del tiempo, la razón finisecular va a forjar un aparato de instituciones y certezas que le permiten salvar los vaivenes del siglo. Pero en la fortaleza de esta cultura restauradora están sus debilidades y lo que pretendía durar para siempre resulta al cabo inadaptable a los cambios. "Yo espero que algún día parecerá una altivez esa osadía de llamarse moderna a sí misma una época" 25 .

Para Ortega, no podemos escapar al drama de la historia, porque la historia no tiene un fin, no hay un sendero de modernidad o un camino que nos ponga fuera de peligro ${ }^{26}$. Lo que podemos es rastrear el sentido de cada momento histórico, una salida virtuosa para los retos del presente; ésta es la tarea de la inteligencia. Hay generaciones — advierte Ortega - que pueden sumarse a la ola modernidad en marcha y limitarse a replicar lo ya sabido. Pero en otras coyunturas, como la que le ha tocado

${ }^{23}$ Ortega y Gasset, J.: El tema de nuestro tiempo..., op. Cit., p. 111.

24 Ortega y Gasset, J.: El tema de nuestro tiempo..., op. Cit., p. 61.

25 Ortega y Gasset, J: 'Nada moderno y muy siglo XX', El Espectador (1916-1934) en Obras completas. Tomo 2, Taurus, 2004, pp. 165-8.

26 "El proceso histórico es una serie de peripecias sin ley, sin sentido. No es posible por tanto una ciencia histórica, que pueda descubrirse, que tenga sentido", Ortega y Gasset, J.: El tema de nuestro tiempo..., op. cit., p. 85. 
vivir, uno no puede conformarse con las ideas heredadas, es preciso ser beligerante, disruptivo ${ }^{27}$. Ortega llama a su generación a atender a esta misión histórica.

En este sentido, la generación "orteguiana” o del 14 tiene más en común —esto no debe perderse de vista - con quienes lo intentaron anteriormente sin fortuna, la generación del 98, que con quienes hacen de la razón un instrumento de resistencia al cambio, los anti-modernistas ${ }^{28}$ ("majaderos ahítos de sentido común" - les llama Unamuno-). El espíritu modernista, "lenguaje de la generación del 98" — dirá Juan Ramón Jiménez—, es una llamada a la renovación cultural, presidido por la conciencia de crisis o de agotamiento de los instrumentos de sentido en curso. El ensayismo, ese género más tarde denostado — hemos visto- por "confundir" filosofía con literatura o periodismo, es el correlato filosófico de un arte modernista de formas híbridas (novela ilustrada y decorada, arquitectura de trazos curvos y armonización de estilos,...), que aspira a representar la realidad viva, en movimiento, y a retratar una realidad popular que permanecía oculta a la mirada de la oficialidad restauradora ${ }^{29}$. La renovación del pensamiento pasa por recuperar un sentido dinámico y vivo de lo real, lo que empujará a todas las expresiones culturales a revisar las viejas formas de representar el mundo. En este proceso autocrítico o de apertura a la realidad histórica, está inmerso no sólo el arte modernista, sino la biología "darwiniana" o la física de Einstein ${ }^{30}$; a esta ola está pendiente que sumarse la filosofía.

La filosofía - defiende Ortega - no es un área del conocimiento cualquiera, una rama entre otras, tiene una especial responsabilidad en la gestación de una nueva cultura ecuménica. La modernización pendiente, el nuevo orden, las categorías o esquemas que den sentido a ese mundo en crisis de comienzos del XX, habrán de surgir de una razón que sepa hacerse cargo de las latencias históricas concurrentes $\mathrm{y}$ articularlas en un nuevo proyecto. Esta urgencia ecuménica es la que pierden de vista otras expresiones culturales, que desde el noventayochismo a las vanguardias - a juicio de Ortega - caen en el error particularista o voluntarista, incapaces de reconocer la complejidad del momento y reconstruir una continuidad histórica, de identificar las instancias reorganizadoras de la vida comunitaria. Ortega tampoco acertará con un diagnóstico histórico, si bien ensaya diversas "soluciones" al problema español, primero, y europeo, después, antes de sucumbir definitivamente en el pesimismo. En todo caso y con independencia de la fortuna de sus propuestas,

\footnotetext{
${ }^{27}$ Si bien habría generaciones "sordas a las urgentes apelaciones de su vocación, prefieren sestear alojadas en ideas, instituciones, placeres, creadas por las anteriores", Ortega y Gasset, J.: El tema de nuestro tiempo..., op. cit., p. 82.

${ }^{28}$ Que el anti-modernismo es sinónimo de reacción queda de manifiesto en la Encíclica 'Pascendi Gregis' de Pio $\mathrm{X}$, cuyo rechazo del modernismo —esto debería interesarnos— es por ser un pensamiento si método.

${ }^{29}$ Retrato pictórico España Negra; Regoyos, Zuloaga, Nonell, Solana,...

30 Ortega y Gasset, J.: El tema de nuestro tiempo..., op. Cit., pp. 183 y ss.
} 
nos lega un patrón filosófico especialmente valioso para tiempos de crisis. "Nuestra tarea — dice en 1923- se asemeja más al pensamiento radical de 1870 que a la filosofía más próxima" ${ }^{31}$. Filosofía radical es la que pone su mirada irónica en nuestro presente, interrogándose sobre sus fuentes de sentido, sus raíces, tratando de encontrar el camino que las reconduzca.

El interés por la realidad inmediata, concreta, es lo que empujaría a la filosofía a la autocrítica - hemos visto-, al diálogo consigo misma pero también con otros saberes. Otras ciencias — explica en Misión de la Universidad ${ }^{32}$ — no tienen en efecto una vocación autorreflexiva tan intensa como la filosofía, sino que "siguen sus propias necesidades" ${ }^{33}$. Sin embargo, estos saberes resultan interlocutores imprescindibles en la tarea por descifrar el sentido de nuestro tiempo y los límites del mismo. La escapada a esta crisis de modernidad exige de nosotros recuperar noción integral de la cultura. La especialización y "profesionalismo" epistémico —en el que como hemos visto caerá finalmente también la filosofía — han servido de impulso al desarrollo científico, pero "al no ser debidamente compensados" — dice Orte$\mathrm{ga}^{34}$ - , pagaremos el efecto destructivo de perder de vista lo común. La conciencia de crisis es la del carácter histórico de nuestros saberes y, por tanto, de la necesidad de mantener abierto el diálogo entre ellos (y con la realidad), para llegar a entender lo que escapa a los márgenes positivos del entendimiento, lo que escapa a la tiranía de lo dado.

\section{Algunas conclusiones para nuestro presente}

LA GUERRA es EL DESENLACE De ESTA CRISIS española, como lo será luego de la mundial. La posición de Ortega provoca decepción entre los derrotados, sin aplacar tampoco el recelo de los vencedores, lo que va a hacer que se disipe su figura como intelectual de referencia, que fue durante el primer tercio de siglo. Esto no impide que el patrón orteguiano, su modelo filosófico, pueda sobrevivir entre sus discípulos del exilio (Salinas, Chacel, Guillén, Castro, Zambrano, Gaos,...), como ha explicado Jorge Novella ${ }^{35}$. Ni significa tampoco que no sean reconocibles, al menos

\footnotetext{
31 Ortega y Gasset, J.: El tema de nuestro tiempo..., op. Cit., p. 35.

32 Ortega y Gasset, J.: Obras completas. Tomo 4, Revista de Occidente, Madrid, 1966, p. 343.

33 "A la ciencia le trae sin cuidado nuestras urgencias y siegue sus propias necesidades. Por eso se especializa y diversifica. La cultura va regida por la vida como tal, tiene que ser en todo instante un sistema completo, integral, estructurado", Ortega y Gasset, J.: Obras completas. Tomo 4, Revista de Occidente, Madrid, 1966, p. 343.

34 Ortega y Gasset, J.: Obras completas. Tomo 4, Revista de Occidente, Madrid, 1966, p. 325.

35 Novella SuÁrez, J.: 'Las estelas de Ortega' en El ensayo como género literario, Universidad de Murcia, 2005, pp. 111-130.
} 
episódicamente, "estelas orteguianas" en el interior; los trabajos de Moreno Pestaña y Francisco Vázquez dan testimonio de algunas de ellas (el debate Bueno-Sacristán, vanguardismo de los 70's o la figura de Aranguren ${ }^{36}$ ). En esos casos puede detectarse una influencia muy desigual de las lecturas de Ortega, más presente en Sacristán y Aranguren que en los jóvenes nietzscheanos. Lo que sí tienen en común estos autores son pautas similares a las que Ortega prescribe para una filosofía en tiempos de crisis: preocupación por el devenir del presente y examen crítico a la filosofía que lo sustenta. Ortega es tan sólo uno de los recursos que éstos tienen a mano, son las urgencias epocales las que dictaminan el modelo filosófico, las que emplazan a una filosofía de crisis.

La normalización democrática ha demandado como pauta general otro modelo de filosofía, como explican los trabajos referenciados al comienzo de este artículo, pero también otros ${ }^{37}$. El imperativo cultural del consenso, que trae consigo la transición democrática, encaja bien - explica F. Colom - con una filosofía de carácter más normativista que histórico-crítico, lo que justificaría la amplia recepción que han tenido entre nosotros autores como Rawls o Habermas ${ }^{38}$. El esfuerzo de importación y especialización filosófica en las últimas décadas habría conducido a la normalización de la filosofía española, lo que está en el haber de la generación impulsora ${ }^{39}$. Sin embargo, como advirtiera Ortega, el descuido de la realidad histórica no hace sino que ésta retorne convulsivamente. La normalización filosófica será interrumpida de nuevo por una conciencia de crisis, por la necesidad escapar a una filosofía de autoconsumo, a los cánones fosilizados y las estrecheces disciplinarias.

Esta conciencia de crisis estaría manifestándose ya en la filosofía española contemporánea, si atendemos a ciertos síntomas. El principal es la existencia de una creciente preocupación por la actualidad, por hacer filosofía del presente. Esto es algo fácilmente detectable para quien permanezca atento a las convocatorias de congresos y de publicaciones en nuestra esfera filosófica. También se plasma en las lecturas e investigaciones de autores más jóvenes, interesados ya no tanto en la "teoría de acción comunicativa" de Habermas, como en Zizek, Rancière, Laclau,

\footnotetext{
${ }^{36}$ Con relación a estos tres episodios pueden consultarse respectivamente: Moreno Pestańa, J.L.: 'Tan orteguianos como marxistas: una relectura del debate entre Manuel Sacristán y Gustavo Bueno Vázquez', Anales del Seminario de Historia de la Filosofía, 28, 2011, pp. 229-252. Vázquez, F.: Hijos de Dionisos. Sociogénesis de una vanguardia nietzscheana (1968-1985), Biblioteca Nueva, Madrid, 2014. García-Santesmases, A.: 'EEran de barro nuestros maestros?', Isegoría, 31, 2004.

${ }^{37}$ Colom González, F.: 'Los usos políticos de la filosofía: Afinidades electivas en la transición española a la democracia', Estudios Políticos, 22, 2003. Ródenas P.: 'El filosofar político español del siglo XX. (Una interpretación poli(é)tica de sus tres momentos)', Laguna: Revista de Filosofía, 39, 2016. Bolado, G.: Transición y recepción: la filosofía española en el último tercio del siglo XX, Sociedad Menéndez Pelayo, Santander, 2001.

${ }^{38}$ Colom González, F.: 'Los usos políticos de la filosofía...', op. cit. pp. 76 y 82.

39 VÁzquez, F:: 'Javier Muguerza y la normalización de la filosofía española', op. cit.
} 
cuyos trabajos tematizan expresamente el presente y tratan de descifrar el sentido del tiempo histórico que habitamos. Pero tampoco se limita a la recepción de análisis importados, sino que abundan cada vez más los filósofos con vocación de intervenir y tematizar la circunstancia española (César Rendueles, Ma Eugenia Palop, Germán Cano, Amador Savater, Moreno Pestaña, Eduardo Maura, Jordi Mir,...). Este fenómeno no es desde luego privativo del campo filosófico, sino que se inserta en un proceso de impugnación cultural y epistémica generacional, que es extensivo a otras ciencias sociales. Esta ola de interés científico por la circunstancia, lo que habría creado a su vez son ciertos brotes de comunidad interdisciplinaria, propiciando encuentros y escenarios de debate sobre la que es una preocupación común y que nos emplaza a salir del nicho académico.

Nuestra crisis habría dado lugar por lo tanto a una nueva generación de "orteguianos" que ejercen de ello de manera más o menos consciente. Hemos defendido también que no es necesario siquiera haber leído a Ortega para practicar una filosofía de crisis o "radical" — como éste la llama—. Pero una lección "orteguiana" queda pendiente de ser recibida y quizá pueda sernos útil; y es que "radical" no significa romper con el pasado, sino reconstruir sus raíces históricas, buscar los hilos de continuidad que den un nuevo sentido al presente. Es desde luego tarea compleja la que le asigna Ortega al filósofo, más sencillo es sin duda desentenderse de la historia y resolver que fue todo un erial. 


\section{Referencias Bibliográficas}

Artime, M.: España. En busca de un relato, Dykinson, Madrid, 2016.

Bolado, G.: Transición y recepción: la filosofía española en el último tercio del siglo XX, Sociedad Menéndez Pelayo, Santander, 2001.

Campillo, A. y Manzanero, D. (coord.): 'Actas del I Congreso internacional de la Red española de Filosofía', http://redfilosofia.es/congresolactas/

Colom González, F.: 'Los usos políticos de la filosofía: Afinidades electivas en la transición española a la democracia', Estudios Políticos, 22, 2003, pp. 61-82.

Díaz Álvarez, J.: 'Las dos muertes de Ortega, a propósito de la norma de la filosofía', Revista de Estudios Orteguianos, 28, 2014, pp. 186-194.

García-Santesmases, A.: ‘¿Eran de barro nuestros maestros?’, Isegoría, 31, 2004, pp. 255-266.

— 'La transición filosófica. Reflexiones político-intelectuales', Circunstancia, 30, 2013.

López Aranguren, J.L.: Moral y sociedad. La moral española en el siglo XIX, Cuadernos para el diálogo, Madrid, 1966.

— Memorias y esperanzas españolas, Taurus, Madrid, 1969.

Morán, G.: El maestro en el erial. Ortega y Gasset y la cultura del franquismo, Tusquets, Barcelona, 1998.

Moreno Pestaña, J. L.: La norma de la filosofía. La configuración del patrón filosófico español tras la Guerra Civil, Biblioteca Nueva, Madrid, 2013.

— 'Tan orteguianos como marxistas: una relectura del debate entre Manuel Sacristán y Gustavo Bueno Vázquez', Anales del Seminario de Historia de la Filosofia, 28, 2011, pp. 229-252.

Novella Suárez, J.: 'Las estelas de Ortega' en El ensayo como género literario, Universidad de Murcia, 2005, pp. 111-130.

NúñEz Ruíz, D.: La mentalidad positiva en España: desarrollo y crisis, Tucar, Madrid, 1975. 
Ortega y Gasset, J.: Obras completas. Tomo 1 y 4, Revista de Occidente, Madrid, 1966.

- El tema de nuestro tiempo, Alianza, Madrid, 1981.

- Obras completas. Tomo 2, Taurus, Madrid, 2004.

Perojo, J.: 'Objeto de la filosofía en nuestros tiempos', Revista Europea, 70 , 1875, pp. 641-650.

RóDenas, P.: 'El filosofar político español del siglo XX. (Una interpretación poli(é)tica de sus tres momentos)', Laguna: Revista de Filosofía, 39, 2016, pp. 9-38.

VÁzQUEZ, F.: La filosofía española: herederos y pretendientes. Una lectura sociológica (1963-1990), Abada, Madrid, 2009.

- 'Javier Muguerza y la normalización de la filosofía española' en Rodríguez Aramayo, R. y otros (ed.): Diálogos con Javier Muguerza, CSIC, Madrid, 2016, pp. 145-162.

- Hijos de Dionisos. Sociogénesis de una vanguardia nietzscheana (1968-1985), Biblioteca Nueva, Madrid, 2014.

Villacañas, J.L. (coord.): Kant en España: el neokantismo en el siglo XIX, Verbum, Madrid, 2006.

DOI: http://dx.doi.org/10.15366/bp2018.18.013

Bajo Palabra. II Época. No18. Pgs: 273-290 
